Preprints of the

Max Planck Institute for

Research on Collective Goods

Bonn 2007/12

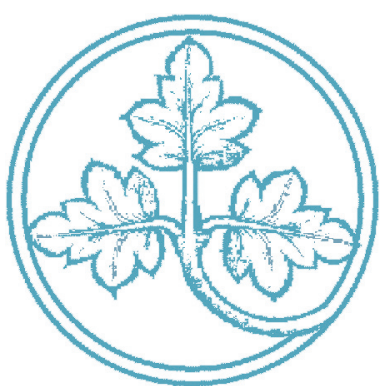

Institutions for

Intuitive Man

Christoph Engel

This paper can be downloaded free of charge from the

Social Science Research Network at http://ssrn.com/abstract=1015765 


\title{
Institutions for Intuitive Man
}

\author{
Christoph Engel
}

August 2007

Max Planck Institute for Research on Collective Goods, Kurt-Schumacher-Str. 10, D-53113 Bonn http://www.coll.mpg.de 


\section{Institutions for Intuitive Man*}

\section{Christoph Engel}

I. Institutions and Behaviour 1

II. The Incentive Story 3

1. Social Problems are Dilemma Situations 3

2. Behavioural Critique 4

3. Critique of the Critique 5

4. Implications for Institutional Design 6

III. Navigating a Fundamentally Uncertain World 10

$\begin{array}{ll}\text { 1. Defining Uncertainty } & 10\end{array}$

2. Decision Making Adapted to a Fundamentally Uncertain World 11

3. Intuition as a Solution to Social Problems 13

4. Intuition Misled 14

5. Implications for Institutional Design 15 


\section{Institutions and Behaviour}

People want to be in control. This at least is a cultural trait of modern Western civilisations. By definition, the non-conscious mental apparatus is not under (direct) conscious control. In the past this has led to exorcism, aiming at liberating the victim from the foreign being by which it is possessed. Freudian psychoanalysis sees the subconscious as the source of serious mental disorder. This paper adopts a more pragmatic perspective. Like any human ability, the non-conscious mental apparatus is assumed to serve a function that, at least in the past when the neuronal structure underlying it has developed, gave human genes an evolutionary advantage. Actually, the paper tries to demonstrate that this advantage is large, and that it persists. However, what is beneficial in most contexts can be dysfunctional in others. It can be in the best interest of the individual, and of society for that matter, to exploit the power of intuition, or to prevent intuitive decision making from doing harm, depending on the specific context. To that end, the individual can design its own decision aids. It can voluntarily seek the support of a coach, or of technology. Yet modern societies do not always wait for that. Formal and informal institutions impose themselves. The intention can be paternalistic. They can aim at curing a perceived social ill. Or they can merely exert power to exploit those who are under their spell.

There are many reasons why institutional designers ought to be cautious. Many institutions are informal, and informal institutions frequently emerge, rather than being purposefully designed (Hodgson 1988). Likewise, the target of institutional intervention, human behaviour, is usually socially embedded (Granovetter 1985). In order to be effective, institutional intervention must therefore set in motion a learning process in its addressees (Engel 2004b). Those deciding on the introduction of new institutions are usually not disinterested (Buchanan and Tullock 1962). This does not necessarily imply that existing formal institutions miss their stated purpose of social betterment. But they are likely to pick those solutions that give well organised political forces a distributional advantage (Knight 1992). Once the legislator has promulgated a new rule, it is handed over to the legal system. Like any subsystem of society, the legal system will apply its own internal logic, which may well be at variance with the original political intention (Teubner 1989). Conversely, institutional addressees have the ability to creatively mute the institution (Wegner 1997).

Despite of all these caveats, in modern industrialised countries, the legislator produces thousands of new rules in a year. If there is a written constitution, and a Supreme Court to enforce it, the legislator must be able to defend any new intervention into freedom or property. It must be able to tell a consistent story why there is a social problem, and how it is solved by the intervention. Such stories also help in generating political support. Moreover, seeing a new bill through to adoption requires a lot of zeal, and may well be costly, e.g. in terms of log-rolling. One must assume a high degree of illusionary thinking to claim that all or at least most of this activity misses the point. If institutions are, at least in principle, effective, institutional designers want to reconstruct them as governance tools, curing a (perceived) social ill. 
Traditionally, social problems are reconstructed as incentive problems. Individually, institutional addressees are better off if they behave in a socially detrimental way. Institutional intervention realigns individual with social well-being. This reconstruction relies on rational choice theory. Rational choice theory has been exposed to two lines of criticism. The first line focuses on behavioural assumptions (Kahneman and Tversky 2000). It accepts rational choice theory to be the norm and is interested in the question whether human decision-makers live up to this norm. It thus explores a potential gap between the norm and the neuronal and psychological algorithms by which human decision-makers try to implement the norm. Actually it is only in this outside perspective that rational choice theory advances to a behavioural norm. In positive economic theory it is only a conceptual tool. Neoclassical economists do not claim that people truly take decisions in accordance with the axioms of rational choice theory. They only make this assumption to understand how behaviour responds to changes in the opportunity structure (Friedman 1953).

The second line of criticism focuses on the norm. It is an established piece of wisdom from normative philosophical theory that all norms for good behaviour ultimately rest in a specific construction of reality (Kersting 1994). The critics of rational choice theory claim that this theory assumes an inappropriately certain world (Gigerenzer, Todd et al. 1999). Rational choice theory only works if individuals interact in a relatively certain world. At the minimum, all interacting must hold the same beliefs about how their interaction partners reconstruct the situation (Savage 1954). Usually, rational choice models assume a well-defined problem. They exclude situations of ignorance (Kirzner 1994), usually also situations of uncertainty. In rational choice theory, a situation is called uncertain if the problem space is well-defined, but there is uncertainty about the probabilities attached to each potential state of nature. If probabilities are known, this is called risk (Knight 1921). In situations of risk, expected values may be calculated.

If one properly accounts for the non-conscious mental abilities, the first line of criticism is considerably weakened. Specifically, at the non-conscious level, human decision-makers have many more cognitive resources at their disposition. However, the second line of criticism gets additional support. Not only is rational choice theory an inadequate reconstruction of decisions in a fundamentally uncertain world. Many features of the non-conscious mental apparatus are highly functional precisely if the individual has to routinely decide on an incomplete factual basis. In the following, both stories shall be sketched.

\section{The Incentive Story}

\section{II.1 Social Problems are Dilemma Situations}

The incentive story is epitomised by the prisoner's dilemma. Everyone is best off if others contribute to the public good, while she gets a free lunch. Writing $\mathrm{C}$ for contribution, and D for defection, and using the first letter for one's own action, and the second for the action of others, in a prisoner's dilemma each individual holds the following preferences: 


$$
\mathrm{DC}>\mathrm{CC}>\mathrm{DD}>\mathrm{CD}
$$

This constitutes the following game:

\begin{tabular}{|c|c|c|}
\hline & contribution & defection \\
\hline contribution & 2,2 & $0, \underline{3}$ \\
\hline defection & $\underline{3}, 0$ & $\underline{1}, \underline{1}$ \\
\hline
\end{tabular}

Figure 1

Prisoner's Dilemma

The numbers in the cells are the players' payoffs, where the first number is the payoff of the row player, and the second number the payoff of the column player. Payoffs are represented ordinally, i.e. by the rank in the respective player's preference order. Best responses are underlined. An equilibrium (in pure strategies) presupposes that two best responses come together in one cell. The only cell for which this is true is the defection/defection cell. This is a dilemma since both players would be better off contributing. This would give both of them their second best outcome, rather than only the third best. However, if they only interact once, and if binding and enforceable agreements are not available, the parties miss this outcome. A combination of greed and fear leads to the socially detrimental result (Macy and Flache 2002). Greedy individuals try to get at their individually best outcome, the free lunch. Fearful individuals anticipate this, and defect because they do not want to be the sucker.

Although game theorists rightly caution against the abuse of this model, it still captures the essence of problems as diverse as climate change, arms races, or incentives for innovation in the absence of intellectual property (Hardin 1968). Relying on the sovereign forces of the state, institutional intervention is able to change a prisoner's dilemma so that the socially desirable result is achieved. There are several options for this. A tax may reduce the benefit from unilateral defection. A subsidy may increase the benefit from unilateral contribution. Those who have contributed may be given the enforceable right to exclude those from the benefit who have not. At a first stage, the players may be allowed to conclude a binding and enforceable contract (Baird, Gertner et al. 1994).

\section{II.2 Behavioural Critique}

A prisoner's dilemma is a dilemma, because either player exclusively considers her own utility. In so doing, she is smart. She not only correctly assesses which outcome she expects in every possible state of the world. She also assumes that all others with whom she is interacting do the same. Given this assumption, she calculates a best response function. She finds her action by maximising over this function (Fudenberg and Tirole 1991). In all but extremely simple games 
this is a daunting intellectual task. For a long time, critics have objected that only daemons, not humans are able to perform the necessary intellectual operations (Simon 1957; Gigerenzer, Todd et al. 1999). Indeed, experimental evidence shows that untrained subjects violate all kinds of mathematical and statistical norms (Conlisk 1996).

The critics have concluded that rational choice models are inappropriate to capture behaviour in real-life situations. They have suggested that individuals instead use radically simple decision rules, which they call heuristics. Heuristics deliberately ignore information. They often are lexicographic. Decision makers go through predefined decision trees. They only go to lower branches if the criteria for taking a decision at a higher branch have been inconclusive. Normally, the criterion at each branch is just one cue. Similar rules tell the decision maker how much effort she should invest in searching for evidence. In order to keep this effort low, search usually is stopped early on (Gigerenzer 2004).

\section{II.3 Critique of the Critique}

If this is an accurate model of human decision-making, the implications for institutional design are profound (Gigerenzer and Engel 2006). But does the approach rest on an incorrect factual basis? Is the idea mistaken that human cognitive abilities are severely limited? Specifically, are the apparent limitations confined to conscious reasoning, whereas the non-conscious mental apparatus offers so many resources that the quest for radically simple decision rules is no longer warranted? Does the heuristics approach suffer from aiming too high? Is the heuristics program only justified if the decision rule must remain the same if it is performed consciously? Is rational choice thus reinstalled, once one properly accounts for non-conscious abilities? Specifically, does rational choice theory turn out to have not only paramorphic, but even isomorphic quality (cf. Fischhoff, Goitein et al. 1981)?

There is indeed evidence pointing into this direction. Psychologists have demonstrated that individuals take a large amount of evidence into account when deciding on a problem with multiple attributes (Glöckner 2007). Neuroscientists have shown that even monkeys carefully record information on cue validities, and that they use it in a way that can be modelled by one of the most demanding concepts of rational choice theory, Bayesian updating (Glimcher 2003). The human brain is much larger than the brain of monkeys. It is therefore highly plausible that human decision-makers do not only possess the same ability, but that they are even better at it. Anecdotal evidence supports this. If people did not possess a powerful non-conscious mental apparatus, speed reading would not be a possibility. In experts, a lack of conscious awareness is often taken to be a sign of professionalisation (Coward 2005:323).

Before institutional intervention can be targeted to the non-conscious mental abilities, one should, of course, better understand them. Consciousness only speaks to mental awareness, which is a precondition for deliberate online control. It does not explain how the information is processed non-consciously. It seems that several inputs are processed in parallel. Parallel con- 
straint satisfaction models explain decision-making the following way: the option is chosen that receives the highest activation, provided the system has reached a pre-defined level of stability, due to attempts at reducing local conflicts between positive and negative activation (Glöckner 2007). To consciousness, only the result of this process is sent back. It is perceived as an intuition. Here, much more knowledge is obviously needed.

\section{II.4 Implications for Institutional Design}

Even at this early stage, however, first implications for institutional design can be fleshed out. They point in two opposing directions. If the non-conscious mental apparatus is indeed so much more powerful than the conscious apparatus, institutions should see to it that, in appropriate circumstances, decision-makers are free to use the better mental machinery.

For that purpose, sometimes it will be enough to just point them into the right direction. A picture says more than a thousand words, they say. Arguably this is due to the fact that pictures convey a lot of information at once that the non-conscious apparatus is able to handle properly. Specifically, pictures are able to inform about a complex relational graph, with no need to give an explicit definition of the individual relations. Normally, there is not much opposition to using pictures. It may suffice to encourage decision-makers to rely on their visualising skills.

If information is processed non-consciously, however, those relying on this information give away control. They at most can use their guts to decide whether they feel comfortable with the resulting intuition. It may be necessary to train people that they should indeed trust their intuitions. This will likely not be appropriate in all circumstances. Institutions could therefore see to it that addressees gain expertise at the meta-level, learning about situations where intuitive decision-making is indeed best policy. The institutional arrangements for professional training may be read as doing exactly this. Moreover, accountability research shows that, with raising stakes, people work harder, but are not necessarily smarter (Wilson and Schooler 1991). They zero in on what they are good at doing. And they seek out for justifications should ambient risks materialise (Tetlock 1985). Where intuitive decision-making is socially desirable, institutions should therefore ostensibly not hold decision-makers liable. An example of this are rules that strictly limit the personal liability of public officials. Another example is the business judgement rule, that shields managers from personal liability (Hansen 1993).

Conversely, although relying on intuition would be good for decision quality, institutional designers may want to impose conscious decision making for competing normative reasons. If they do, they frequently face a dilemma. Furthering the competing goal comes at the cost of very likely deteriorating decision quality. Good institutional design ought to get this balance right. Nonetheless, intuitive decision-making may be unwanted. Institutional intervention may be meant to change the way how addressees take a decision, rather than (only) behavioural output (Engel and Weber 2006). The main three reasons for this are related to each other. 
By definition, non-conscious decision-making is not under conscious control. Consequently, the person who has had the intuition is unable to convey to outsiders anything but the final outcome. At most, learning that one person has had a certain intuition may trigger the non-conscious formation of the same intuition in an outsider. Otherwise they must trust the foreign intuition. In many contexts, this is deemed insufficient. For instance, most legal orders oblige judges to give explicit, written reasons for the decisions they are taking on behalf of the People (Engel 2004a). This is not only a measure of social hygiene. If their intuitions go unchecked, judges might non-consciously - have been influenced by stereotypes and prejudices, rather than unbiased judgement. Same for legislators and regulatory agencies. And tort law effectively forces doctors to be able to give explicit reasons for the treatments they order. In the light of the scandals that led to the Sarbanes-Oxley Act, shareholders increasingly force Chief Executive Officers to give reasons for their business decisions as well.

The second and third reasons become even stronger once one drops the assumption of a well defined problem space. But even under the more restrictive assumption predictability and regulability are an issue. The power of intuition then results from the fact that, non-consciously, large amounts of information may be processed in very little time (Kahneman and Frederick 2002). This information need not be taken online from the environment. It may be retrieved from memory. This makes it difficult for interaction partners to predict foreign intuition. They may have overlooked those of the many facets of the situation that have induced the decision maker to form a certain intuition. Even with perfect attention to the situation, it is impossible to second guess the elements of declarative memory that the decision-maker's brain adds to the material from which it forms the intuition. One would have had to accompany the decision maker throughout her entire previous life. With imperfect prediction, social interaction becomes at least risky, if not impossible to bring about (Engel 2005). Of course, intuitive decision-making is not always and necessarily less predictable. An example to the contrary is behaviour guided by strong and persistent emotions, like vengeance.

Predictability is also of utmost importance for regulation. Most social problems originate in human behaviour. Admittedly, there are exceptions. If a volcano bursts, one cannot hold a person liable. All one can do is putting in place an early alert system, and evacuate neighbouring regions once the alert system indicates present danger. However, an ever smaller part of institutions is meant to contain pure natural risk. Even risks as apparently natural as global warming are very likely to result from human behaviour. The large majority of problems addressed by institutions result from strategic interaction. They are thus purely human in origin.

Whenever human behaviour is at least part of the explanation for the problem, regulators must get this behaviour right. They are in the business of prediction. Prediction is inevitable for the second component of institutional design: defining the precise shape of the institution itself. This presupposes anticipating how addressees will react to the intervention. If they use their intuition for the purpose, the intervention is bound to be only one out of many elements being processed. It is next to impossible for institutions to get addressees' intuition under control. Understanding the non-conscious mental apparatus, therefore, radicalises an observation from the evolutionary 
theory of institutions. The effect of institutional intervention is not only unpredictable if addressees, on purpose, try to creatively mute the impulse (Wegner 1997). The predictability problem already exists whenever addressees use their non-conscious mental apparatus.

In appropriate contexts, institutional designers may respond by shifting to two-level governance. By a first intervention they induce addressees to keep their decision under full conscious control. The second intervention exploits the much better predictability for doing something about the underlying social problem. Visibly raising stakes is the most popular way to do this. The most drastic intervention to that end is holding managers liable under criminal law, as in the environmental legislation of many countries (for an overview see O'Hear 2004). A justification requirement has a similar effect (Tetlock, Skitka et al. 1989). However, this strategy comes at a high price. Precisely since the non-conscious mental apparatus is so much more powerful, institutional designers face a hard choice between higher predictability and better decision quality.

While predictability is the most visible, it is not the only challenge to regulability resulting from intuition. By definition, only the final outcome becomes conscious. The mental process of forming the intuition is beyond conscious control. It is therefore not a matter of willpower whether a person has an intuition, and which are its contents. The standard suggestion from rational choice theory for the design of institutions is mute. Raising stakes, be it via imposing sanctions or handing out subsidies, is pointless if the addressee is unable to control the target activity. Specifically, institutional designers would have to be sure that higher stakes do not only influence conscious decision-making, but find a way to impact on the non-conscious formation of an intuition. Preparing for future intuitive decision-making may be easier to influence.

This casts new light on the legal concept of negligence. Negligence is stricter than intent. A tort feasor, or a person bound by a contract, is not only sanctioned if she has violated her duty on purpose. She is also held liable if she could have been expected to prevent the violation from happening. It would make sense to at least partly reconstruct this as liability for not having properly trained one's intuitions. If this holds true, it has an important implication for institutional design. Since training intuitions takes time, effective institutional intervention must start early on. Institutional designers, and the political and legal constituencies controlling them, must be sufficiently patient. It is possible that additional institutions must see to it that the respective task is only performed by those who have undergone training. The institutional arrangements around the liberal professions may serve as an illustration. For instance, the training of future doctors is not confined to transmitting explicit knowledge. They are also sent to hospital, to practice under supervision. This is meant to imbue them with the implicit knowledge of the discipline (cf. on the distinction between explicit and implicit knowledge Cowan, David et al. 2000).

While the non-conscious mental apparatus is able to handle a huge amount of information in very little time, it might well not be perfect. Even the many more resources must have their limits. Take the following, deceptively simple problem. Two players interact. Each of them has three options. At every instance of interaction, the options of either player may therefore be combined in nine different ways. Each player may rank each of these nine outcomes differently. 
This apparently simple structure already makes for $9 !=362880$ possible different games. It is possible that the human mind is able to solve problems as complex as this. The fact that people solve the travelling salesman problem so easily points into this direction. Doing so involves mental operations in this order of complexity. But ultimately, there must be a limit. If each player has four options this already makes for $16 !=20,922,789,888,000$ combinations. Now interacting with just one other person that may order 4 items in her utility function in every possible way is not an outlandish situation. It is therefore highly likely that there are situations for which even the limitations of the non-conscious mental apparatus matter.

It still seems to be largely unclear whether the non-conscious mental apparatus not only has quantitative, but also qualitative limitations. The question is related to a second one. Why has it given the human species an evolutionary advantage to develop the ability to consciously override the non-conscious apparatus? Does the non-conscious apparatus have too many degrees of freedom? A hint comes from twin studies. Twins tend to create more divergence than they would have generated, had they grown up in different places. Does the human mind thus suffer from an embarrassment of riches? Does the non-conscious apparatus lack the ability to self-programme, or to direct an active search for information? Is it too easily trapped by the surface structure of a problem, and risks to neglect what is already known about the underlying basic structure? Related to this: is it difficult for intuitive decision-making to ignore history and to decontextualise? Is intuition too good at finding an acceptable solution for the problem at hand, and does it run the risk of neglecting the consequences for future similar situations? Are institutions needed where the socially desirable outcome is counterintuitive?

It probably is too early to build institutional interventions on any of these speculations. Until our knowledge about the limitations of the non-conscious mental apparatus has further advanced, these ideas may, however, at least serve as an additional explanation for interventions that are already found in institutional practice. The last point provides a good illustration for this. In principle, the law of torts is an elegant institution. All the legislator has to do is to promulgate that tortfeasors are held liable, maybe with the restriction that they can be found negligent. What this general rule means in practice is, step-by-step, developed by the courts, in the light of concrete conflicts. Through this decentralised mechanism, much more local knowledge goes into the actual shaping of the rule. However, since the general rule, at least originally, is underspecified, the courts are likely to rely on their intuition when making it more concrete. Many have complained that this often creates a bias. In the interest of being fair with the victim, the courts generate rules that, for the general public, are overly stringent (Rachlinski 2000). It has been one of the hallmarks of law and economics to teach the courts to see the long-term implications of negligence standards (Posner 2003). Thus far, this discussion has been using different language. But one might reconstruct the law and economics of torts as a tool for correcting intuitive decisionmaking where it leads to socially undesirable results.

Along the same lines, one may wonder whether institutions play a role in shaping the interaction between the intuitive and the deliberate mental apparatus. It has been claimed that the nonconscious and the conscious, the intuitive and the deliberate, the parallel and serial are not tightly 
separated from each other, but may interact (Strack and Deutsch 2004). Again it probably is too early to suggest new institutions for the socially more desirable fine tuning of this interaction. Suffice it to point to one existing institutional arrangement that may be reconstructed as doing exactly this. It goes to the core of the legal profession. Decision-making in court has been demonstrated to heavily rely on „coherence-based reasoning“ (Simon 2004). Given the institutional framework, and the need to give explicit reasons for the decision taken in particular, one could not possibly claim that judges exclusively rely on their intuition. But it is also beyond doubt that legal decision-making is not just a matter of calculus. The legal method is hermeneutical. It asks the lawyer to match an overly rich reality to an abstract rule. Judges get at this syllogism by deliberating, permanently checking inputs and potential outcomes back with their intuition. In light of this, one may interpret the compulsory training of future lawyers, and the organisation of the court system, as tools for bringing about the socially desired interaction between intuition and deliberation.

Finally, clever institutional design might be able to get at the best of both worlds. There might be interventions that leave enough room for the power of intuition, and nonetheless provide society with accountability, predictability and regulability. Again judicial procedure might provide an illustration. Judges are obliged to give explicit reasons for their decisions. But they are not obliged to report the mental process by which they have found the solution to the case. The separation between the context of discovery and the context of representation might do the trick (Engel 2004a). It has been claimed that this is also how morality serves as a post hoc control of individual behaviour (Haidt 2001). If mere predictability is enough, standardising context might suffice, if certain intuitions predictably go with this context (Engel 2005). This might be due to the fact that the mental representation of the standardised setting is reliable. On this, obviously more experimental work is needed.

\section{Navigating a Fundamentally Uncertain World}

\section{III.1 Defining Uncertainty}

As long as individuals have to make choices from a well-defined problem space, the (evolutionary) advantage of intuition boils down to a question of quantity. If individuals rely on their intuition, they can muster many more resources for decision-making. The fact that the problem, or the socially desired solution, are complicated does not necessarily mean that the individual is unable to solve it. One only sees the full power of intuition if one drops the assumption that the problem space is well defined. Many problems individuals, and societies for that matter, have to solve are indeed ill-defined. Frequently, social problems are a moving target. At most, the institutional designer is able to show that today's state of the world is at variance with some accepted normative standard. Whether the problem persists in the future depends on a plurality of contextual factors about which the institutional designer can at best hold beliefs. By definition, the future is uncertain. Often, the reconstruction of the present state of affairs also stands on shaky grounds. If one needs time series information to show the existence of a problem, or to say something mean- 
ingful about causality (Leamer 1983), the necessary data will often not be available. Things become worse if individual events must be reconstructed. As court procedure demonstrates, true certainty is almost never achieved. As is well known, eyewitnesses are particularly unreliable. Memory decays over time, and is reconstructive rather than photographic in the first place (Sporer, Malpass et al. 1996).

Moreover, even if, in a categorical sense, the problem is well-defined, it may nonetheless not be rigorously tractable. This statement holds even if one expects the non-conscious mental apparatus to be more powerful than it probably is. In the last section, the reader has been reminded of the fact that an instance of strategic interaction as simple as one having only two players, and only three options for each of them, already constitutes a set of $9 !=362880$ different games. This is not a degree of complexity modern personal computers would shy away from. But a game not more complicated than chess is no longer open to canonical analysis and decisionmaking, although a chessboard does not have more than 64 fields. Of course, Deep Blue has been able to beat the world champion in chess 10 years ago. But in so doing, it did not simply use brute force. It worked with approximations, not with simple calculus ${ }^{1}$. A limit of principle is reached once a problem is „NP-hard“, i.e. if, by calculus, the problem cannot be solved in defined time, whatever the amount of resources used for calculation (Garey and Johnson 1979). This is already the case if the dependent variable is in the exponent, as in the following, deceptively simple, equation

$$
y=a^{x}
$$

where $a$ is a constant, and $y=f(x)$.

Finally, for pragmatic reasons decision-makers may prefer to reduce mental effort and to solve problems in a non-canonical way, although this would in principle be possible. This is indeed what has been found in experiments (Oaksford and Chater 2001). In particular it seems that many people use trust, rather than any version of game theory, to decide upon action in situations of strategic interaction, even if they are experienced (Selten, Mitzkewitz et al. 1997). This may be a strategy to save mental resources for competing tasks. The strategy may also be triggered by time pressure. But it seems that, even beyond such cost-benefit-analysis, most people are „,cognitive misers“" (Tetlock, Skitka et al. 1989:633).

\section{III.2 Decision Making Adapted to a Fundamentally Uncertain World}

As has been explained, the remarkable power of the non-conscious mental apparatus casts some doubts on the first argument brought forward in support of the heuristics programme: cognitive limitations. However, the main argument has always been that most real-life problems are either ill-defined or NP-hard (Gigerenzer 2004). This second argument is not affected by the criticism. But the heuristics programme to date still suffers from a lacuna. By now, there is ample evidence

1 http://www.research.ibm.com/deepblue/. 
that fast and frugal heuristics can indeed perform surprisingly well, although the decision rule asks decision-makers to deliberately ignore most of the available information. However, this statement only holds if the appropriate heuristic is applied. Thus far, the heuristics programme is not able to say much about appropriateness, and even less about the way how people learn about it (but see Rieskamp and Otto 2006). Heuristics are good if and when they are „ecological“. They perform poorly if they are used out of domain (Engel 2006). Intuition provides the missing link. Defining the proper domain of a heuristic, and assessing whether the case at hand fits the definition, is bound to be an information rich activity. Precisely because intuition is able to handle large amounts of information rapidly, it is possible that decision-makers apply a certain heuristic where this indeed leads to good decisions.

Actually, the power of intuition even goes beyond this. As will be explained in greater detail below, decision-makers can use their intuition to match features from the environment to schemas (Bartlett 1932:199-204) and exemplars (Anderson 2000:350-352). In either concept, not each and every element from the description of the schema or the exemplar must be met by observation. Some may miss. It depends on the relevance of the missing element whether the case at hand is nonetheless assimilated to the domain of the heuristic. Intuition has a further advantage for the concept of heuristics. The result of the non-conscious processing can be made consciously available. This opens up the possibility that decision-makers non-consciously check whether they dispose of an appropriate heuristic, and then apply it consciously. This fits the heuristics programme, since this research has normally not specified whether the heuristic is applied consciously or not, and it is certainly open to the idea that the decision tree itself is processed consciously.

But there is an alternative possibility. Decision-making can entirely rest on intuition. If this is the case, the decision maker not only uses a lot of information to assess whether a certain heuristic is applicable. She also takes many elements into account when making the actual decision. Specifically, she may not only consider multiple cues, but also attach different weights to each of them, and allow for cue weights to be changed via the interaction with competing cues (Glöckner 2007). Ultimately, this is an empirical question. The existing evidence makes it likely that the meta-decision how to decide is influenced by the perceived situation and by personality. The stronger the time pressure, and the higher the load of competing tasks, the more parsimonious the decision rule. And some people, most of the time, prefer relatively simple rules whereas others tend to spend more (non-conscious!) effort on the processing of information (Glöckner 2007).

In functional terms, non-conscious parallel processing of information enables decision-makers to use Bayesian statistics (Bolstad 2004). They are thus not confined to using the information to which they have access at the moment of decision making. Rather they can use the new information to update their provisional knowledge about the environment (Oaksford and Chater 1994). They are also able to engage in mental simulation (Stone and Davies 1995). 
All of this is extremely helpful in navigating a (fundamentally) uncertain environment. The individual may find critical situations by looking for outliers: ,something is fishy here”. The early alert system becomes even more powerful if the individual can quickly check whether single features of an otherwise familiar situation are novel, or even similar to the characteristics of a dangerous event. Individuals are able to engage in sense making (Weick 1995), in constructing mental models (Johnson-Laird 1983), and in observational learning (Bandura 1986). They can transpose solutions that have been successful in the past to new situations, once the current problem has been identified as sufficiently similar to the earlier one (Gilboa and Schmeidler 1995). They can thus exploit the power of associations (Coward 2005:305).

\section{III.3 Intuition as a Solution to Social Problems}

Occasionally, once one duly accounts for the power of intuition, there is no longer any need for institutional intervention. In appropriate circumstances, this even holds for the classic rational choice justification for institutional intervention, the prisoner's dilemma. In principle, the dilemma persists if the two players are allowed to communicate. It is in the best interest of both of them to agree on the cooperative solution. However, this only shifts the original conflict to the implementation stage. Once they have agreed, either player is best off if the other is loyal to the agreement while she defects. This even holds if the agreement allows the victim, or any member of a larger group, to impose a sanction on those who violate the agreement. For punishment is costly. Again those are best off who have others do the costly punishing. The original dilemma repeats (Heckathorn 1989).

Lawyers tend to be unconvinced by this story. It clashes with their experience that the conclusion of a contract matters, even if the contract cannot be enforced. The experience is particularly pronounced in public international law. Since there is no world government, the enforcement of international treaties may often not be taken for granted. Nonetheless states are reluctant to accept treaty provisions if they know that they will not want to implement them later on. There are rational choice explanations for this. States might be afraid that they gain a bad reputation, which may be costly in future negotiations. But legal experience seems to point to the fact that there is more to it than just repeated or nested games. One possible explanation of the add on fits here.

It has been demonstrated that people dispose of a very sensitive cheater detection mechanism (Cosmides 1989). Further evidence shows that most people hold strong punishing sentiments if they suspect others to have cheated on an earlier promise (Fehr and Gächter 2000). The combination of both mechanisms offers a solution to the prisoner's dilemma. Players are allowed to communicate, and to punish free riders.

Intuition also helps understand a frequent observation from political practice, and from legal discourse. Since contestants cannot agree on fundamentals, they content themselves with an ,incompletely theorized agreement" (Sunstein 1995). They are happy to agree on an outcome, although each of them may hold different convictions as of why it is justified. This may, of course, 
be due to the fact that each of them is able to give a consistent justification, only starting from different premises. However, in legal practice the experience is a different one. Someone suggests a solution. Everyone quickly accepts it as a good one. Conflict breaks out once one of them starts giving reasons. After a long and vigorous fight they finally agree to leave reasons aside since they still feel happy with the original suggestion for a solution. This line of events can only be explained if some contextual, but hard to formulate, elements push the decisions of all of them into the same direction.

This explanation also holds for another frequent observation. Not so rarely, when they learn about the latest theoretical achievements in one of the social sciences, lawyers respond: oh yes, we have been attentive to this for a hundred years. There have for instance been many legal rules taking care of the anti-commons problem before even the term had been coined (Heller 1998). This statement is not meant to depreciate the advancement of the social sciences. Being able to precisely articulate a problem has value. But the fact that the (legal) solution so often predates the precise formulation of the problem can only be explained if, intuitively and hence nonconsciously, legal decision-makers have already grasped the essence of the problem.

\section{III.4 Intuition Misled}

While intuition thus is a powerful tool for navigating an uncertain environment, it is not foolproof. Intuition can easily be misled. (Experimental) judges have been demonstrated to discount pieces of evidence to generate coherence where the material presented to them did not allow for this (Simon, Pham et al. 2001). Legal professionals have at most a very small advantage over lay people when it comes to telling a credible eyewitness from a lying one. However, they feel much more comfortable with their assessment (Sporer 2007). If decision-makers have been exposed to a biased sample, they build intuitions that are inappropriate for the true population (cf. Fiedler 2000). Interested outsiders can specialise in manipulating foreign intuition to their advantage. A classic is subliminal advertising, where the target group is primed in favour of buying a product without even noticing (Greenwald, Klinger et al. 1995).

Intuition seems to be much better at finding a locally, rather than a globally acceptable solution. Economists for instance claim that non-economists are very bad at capturing multiple, interrelated effects, say the co-presence of substitution and income effects (Hellwig 2006). Note that the explanation for the phenomenon would not be sheer complexity. Rather the non-conscious apparatus would be more or less well prepared to execute some (mildly) complicated mental operation. In this explanation, the problem originates in the fact that socially relevant mental operations are „counter-intuitive“. This might be due to the fact that individuals are genetically prepared to interpret the situation otherwise. Or they might have acquired this inclination through enculturation.

Intuitive decision-making becomes particularly socially disruptive if individuals have to cooperate whose intuitions clash. The problem is so hard precisely because the individuals do not have 
access to the underlying mental process. All they have is the result, the intuition, which they cannot but believe to be true. The very instance that has served to demonstrate the potential of the non-conscious for the solution of social problems also illustrates the most profound risk in this. The prisoner's dilemma is overcome if players use intuition to detect cheaters, and are willing to punish them. But what if cheating is a matter of interpretation? In the standard game presented above, there is no room for ambiguity. Both players have identical endowments. The optimal solution for the community of the two players is precisely defined. The game is fully symmetrical. Both players know this. It is easy for them to calculate their own payoffs, as well as the payoffs of the other player, for each combination of actions. Real life conflicts are hardly ever that clean. The potential for gains and losses is distributed asymmetrically (Rapoport and Chammah 1965). The players are asymmetrically well informed. The structure of the game, and the payoffs are not beyond doubt. The players bring different endowments to the game.

The cheater detection mechanism rests on assessing fairness. Once one goes away from the clean situation, different fairness norms could be applied. Rather than formal equality, desert, entitlement or status could be used (Hoffman and Spitzer 1985; Hoffman, McCabe et al. 1998). Depending on which norm is chosen, the definition of cheating would be a different one. Specifically, while one norm would give one of the players a distributional advantage, a competing one frequently would advantage the other player. Take, for instance, an asymmetric game. Is it unfair for the player who is advantaged by the structure of the game to insist on the equilibrium solution? Unfortunately, individuals have a strong self-serving bias in defining the fairness norm. Actually, they firmly believe that fairness could only be assessed in this, and in no other way (Konow 2005). Their intuition thus traps individuals two times: in picking a fairness norm, and in believing that the other player has cheated since she has violated this norm. In such situations, conflict is bound to escalate. For the first player feels the urge to punish the „cheater“". This player feels treated unfairly, and punishes back (Denant-Boèment, Masclet et al. 2007).

\section{III.5 Implications for Institutional Design}

In principle, in an uncertain environment, the implications for institutional design are similar to the ones sketched for a well-defined problem space. Where intuition is more powerful than conscious deliberation, institutions should build trust in intuition. Where intuition risks being misled in an individually or socially detrimental way, institutions may choose among one of two aims. They may try to induce their addressees to use a less problematic mental mechanism, be that just conscious reasoning, or some combination of intuitive and deliberate elements. Or institutions may try to shape the environment such that addressees form more appropriate intuitions. The problems of control, predictability and regulability are the same as in a well-defined problem space, as are potential solutions.

Suffice it therefore, at this point, to say a word about conflicting intuitions. Social norms have been demonstrated to guide people in the formation of not necessarily identical, but coordinated fairness norms (Kahan 2005). Formal legal rules could have the same effect if they are properly 
translated into more contextualised normative expectations (Engel 2004b). Coordinating intuitions becomes, of course, the easier, the more homogeneous a society. Responses to perceived fundamental uncertainty have been shown to be culturally contingent (Nisbett, Peng et al. 2001; Sperber and Hirschfeld 2004). But making societies more homogeneous will usually not be an option for policymakers. Shaping the representation of the situation, and organising feedback, are at least of some help. 


\section{References}

ANDERSON, JOHN R. (2000). Learning and Memory. An Integrated Approach. New York, Wiley.

Baird, Douglas G., Robert H. Gertner and Randal C. Picker (1994). Game Theory and the Law. Cambridge, Mass., Harvard University Press.

BAndura, AlBert (1986). Social Foundations of Thought and Action. A Social Cognitive Theory. Englewood Cliffs, N.J., Prentice-Hall.

Bartlett, Frederic C. (1932). Remembering. A Study in Experimental and Social Psychology. Cambridge, [Eng.], The University Press.

Bolstad, William M. (2004). Introduction to Bayesian Statistics. Hoboken, N.J., WileyInterscience.

Buchanan, JAmes M. and Gordon Tullock (1962). The Calculus of Consent. Logical Foundations of Constitutional Democracy. Ann Arbor, University of Michigan Press.

Conlisk, JoHN (1996). „Why Bounded Rationality?““ Journal of Economic Literature 34: 669700.

Cosmides, LedA (1989). „The Logic of Social Exchange. Has Natural Selection Shaped how Humans Reason? Studies with the Wason Selection Task.“ Cognition 31: 187-276.

Cowan, Robin, Paul A. David and Dominique Foray (2000). „The Explicit Economics of Knowledge Codification and Tacitness.“ Industrial and Corporate Change 9: 211-253.

Coward, L. Andrew (2005). A System Architecture Approach to the Brain. From Neurons to Consciousness. New York, Nova Biomedical Books.

Denant-BoÈment, Laurent, David Masclet and Charles Noussair (2007). „Punishment, Counter-Punishment and Sanction Enforcement in a Social Dilemma Experiment." Economic Theory ***: ***.

Engel, CHRISTOPH (2004a). The Impact of Representation Norms on the Quality of Judicial Decisions http://ssrn.com/abstract=617821.

ENGEL, CHRISTOPH (2004b). Learning the Law http://ssrn.com/abstract=539982.

Engel, CHRISTOPH (2005). Generating Predictability. Institutional Analysis and Institutional Design. Cambrige, Cambridge University Press.

Engel, Christoph (2006). Social Dilemmas Revisited from a Heuristics Perspective. Heuristics and the Law. Gerd Gigerenzer und Christoph Engel. Cambridge, Mass., MIT Press: 61-85. 
Engel, Christoph and ElKe U. Weber (2006). The Impact of Institutions on the Decision how to Decide http://ssrn.com/abstract=935024.

FeHr, ERnst and Simon GÄChter (2000). „Cooperation and Punishment in Public Goods Experiments.“ American Economic Review 90: 980-994.

FIEDler, Klaus (2000). „Beware of Samples! A Cognitive-Ecological Sampling Approach to Judgement Bias.“ Psychological Review 107: 659-676.

FischHOFF, BARUCH, BERnARD GOITEIN and Zur ShapiRa (1981). „Subjected Expected Utility. A Model of Decision-Making." Journal of the American Society for Information Science 32: 391-399.

Friedman, Milton (1953). Essays in Positive Economics. [Chicago], University of Chicago Press.

Fudenberg, Drew and Jean Tirole (1991). Game Theory. Cambridge, Mass., MIT Press.

Garey, Michael R. and David S. Johnson (1979). Computers and Intractability. A Guide to the Theory of NP-completeness. San Francisco, W. H. Freeman.

GigerenZer, Gerd (2004). Fast And Frugal Heuristics: The Tools Of Bounded Rationality. Handbook of Judgement and Decision Making. Derek Koehler und Nigel Harvey. Oxford, UK, Blackwell.

Gigerenzer, Gerd and Christoph Engel, Eds. (2006). Heuristics and the Law. Boston, MIT Press.

Gigerenzer, Gerd, Peter M. Todd and ABC Research Group (1999). Simple Heuristics that Make us Smart. New York, Oxford University Press.

GILbOA, ItZHAK and DAVID SchmeIDLER (1995). „Case-Based Decision Theory.“ The Quarterly Journal of Economics 110(3): 605-639.

Glimcher, Paul W. (2003). Decisions, Uncertainty, and the Brain. The Science of Neuroeconomics. Cambridge, Mass., MIT Press.

Glöckner, Andreas (2007). Does Intuition Beat Fast and Frugal Heuristics? A Systematic Empirical Approach. A New Look on Intuition. Henning Plessner, Claudia Betsch und Tilmann Betsch. Mahway, Erlbaum: ***.

Granovetter, MARC (1985). „Economic Action and Social Structure. The Problem of Embeddedness.“ American Journal of Sociology 91: 481-510. 
Greenwald, Anthony G., Mark R. Klinger and ERIC S. Schuh (1995). „Activation by Marginally Perceptible (,Subliminal”) Stimuli: Dissociation of Unconscious From Conscious Cognition.“ Journal of Experimental Psychology: General 124: 22-42.

HaidT, JonATHAn (2001). „The Emotional Dog and Its Rational Tail. A Social Intuitionist Approach to Moral Judgment.“ Psychological Review 108: 814-834.

Hansen, Charles (1993). „The Duty of Care, the Business Judgement Rule, and the American Law Institute Corporate Governance Project.“ Business Lawyer 48: 1355-1376.

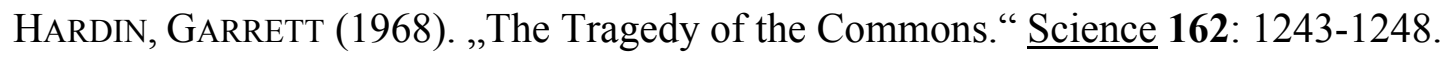

Heckathorn, Douglas D. (1989). „Collective Action and the Second-Order Free-Rider Problem.“ Rationality and Society 1: 78-100.

Heller, Michael A. (1998). „The Tragedy of the Anticommons. Property in the Transition from Marx to Markets.“ Harvard Law Review 111: 621-688.

HellwiG, MARTIN (2006). Zur Kategorie der Kausalität in den Wirtschaftswissenschaften http://www.coll.mpg.de/pdf_dat/2006_10online.pdf.

Hodgson, Geoffrey Martin (1988). Economics and Institutions. A Manifesto for a Modern Institutional Economics. Philadelphia, University of Pennsylvania Press.

Hoffman, Elizabeth, Kevin McCABE and Vernon L. Smith (1998). „Behavioral Foundations of Reciprocity. Experimental Economics and Evolutionary Psychology.“ Economic Inquiry 36: 335-355.

Hoffman, Elizabeth and Matthew L. Spitzer (1985). „Entitlements, Rights, and Fairness. An Experimental Examination of Subject's Concepts of Distributive Justice.“ Journal of Legal Studies 14: 259-297.

Johnson-Laird, Philip N. (1983). Mental Models. Towards a Cognitive Science of Language, Inference and Consciousness. Cambridge, Cambridge University Press.

KAHAn, DAn (2005). The Logic of Reciprocity: Trust, Collective Action, and Law. Moral Sentiments and Material Interests. Herbert Gintis, Samuel Bowles, Robert Boyd und Ernst Fehr. Boston, MIT Press: 339-378.

Kahneman, Daniel and Shane Frederick (2002). Representativeness Revisited. Attribute Substitution in Intuitive Judgement. Heuristics and Biases. The Psychology of Intuitive Judgement. Thomas Gilovich, Dale W. Griffin und Daniel Kahneman. New York, Cambridge University Press: 49-81.

Kahneman, Daniel and Amos Tversky (2000). Choices, Values, and Frames. Cambridge, Russell Sage Foundation; Cambridge University Press. 
Kersting, Wolfgang (1994). Die politische Philosophie des Gesellschaftsvertrags. Darmstadt, Wissenschaftliche Buchgesellschaft.

KIRZNER, IsRAEL (1994). On the Economics of Time and Ignorance. The Market Process. Essays in Contemporary Austrian Economics. Peter J. Boettke und David L. Prychitko. Brookfield, Elgar: 38-44.

Knight, Frank Hyneman (1921). Risk, Uncertainty and Profit. Boston, New York,, Houghton Mifflin Company.

KNIGHT, JACK (1992). Institutions and Social Conflict. Cambridge England, Cambridge University Press.

KonOw, JAMES (2005). „Blind Spots: The Effects of Information and Stakes on Fairness Bias and Dispersion." Social Justice Research 18: 349-390.

LEAMER, EDWARD E. (1983). „Let's Take the Con out of Econometrics.“ American Economic Review 23: 31-43.

Macy, Michael M. and Andreas Flache (2002). „Learning Dynamics in Social Dilemmas.“ Proceedings of the National Academy of Sciences of the United States of America 99: 7229-7236.

Nisbett, Richard E., Kaiping Peng, Incheol Choi and Ara Norenzayan (2001). „Culture and Systems of Thought. Holistic Versus Analytic Cognition.“ Psychological Review 108: 291-310.

OAKSFORD, Mike and Nick CHATER (1994). „A Rational Analysis of the Selection Task as Optimal Data Selection.“ Psychological Review 101: 608-631.

OAKSFORD, Mike and Nick Chater (2001). „The Probabilistic Approach to Human Reasoning.“ Trends in Cognitive Science 5: 349-357.

O'Hear, Michael M. (2004). „Sentencing the Green-Collar Offender. Punishment, Culpability, and Environmental Crime." Northwestern School of Law Journal of Criminal Law and Criminology 95: 133-275.

Posner, Richard A. (2003). Economic Analysis of Law. New York, Aspen Publishers.

Rachlinski, Jeffrey J. (2000). A Positive Psychological Theory of Judging in Hindsight. Behavioral Law and Economics. Cass R. Sunstein. Cambridge, Cambridge University Press: 95-115.

Rapoport, Anatol and Albert M. Chammah (1965). Prisoner's Dilemma. A Study in Conflict and Cooperation. Ann Arbor,, University of Michigan Press. 
RieskAMP, JÖRG and PhilipP E. OTTO (2006). „SSL: A Theory of How People Learn to Select Strategies.“ Journal of Experimental Psychology: General 135: 207-236.

Savage, LeOnARD J. (1954). The Foundations of Statistics. New York, Wiley.

Selten, Reinhard, Michael Mitzkewitz and Gerald R. Uhlich (1997). „Duopoly Strategies Programmed by Experienced Players.“ Econometrica 65: 517-555.

SimOn, DAN (2004). „A Third View of the Black Box. Cognitive Coherence in Legal Decision Making." University of Chicago Law Review 71: 511-586.

Simon, Dan, Lien B. Pham, Quang A. Le and Keith J. Holyoak (2001). „The Emergence of Coherence Over the Course of Decision Making." Journal of Experimental Psychology: Learning, Memory and Cognition 27: 1250-1260.

Simon, Herbert Alexander (1957). Models of Man: Social and Rational. Mathematical Essays on Rational Human Behavior in a Society Setting. New York, Wiley.

Sperber, Dan and LaWrenCe A. Hirschfeld (2004). „The Cognitive Foundations of Cultural Stability and Diversity.“ Trends in Cognitive Science 8: 40-46.

Sporer, Siegfried Ludwig (2007). Evaluating Eyewitness Testimony. The Fallacies of Intuition. The Impact of Court Procedure on the Psychology of Judicial Decision Making. Christoph Engel und Fritz Strack. Baden-Baden, Nomos: ***.

Sporer, Siegfried Ludwig, Roy S. Malpass and Günter KÖHnKen (1996). Psychological Issues in Eyewitness Identification. Mahwah, N.J., Lawrence Erlbaum Associates.

Stone, Tony and Martin Davies (1995). Mental Simulation. Evaluations and Applications. Oxford, UK ; Cambridge, Mass.,, Blackwell.

StRACK, FritZ and Roland DeUtsch (2004). „Reflective and Impulsive Determinants of Social Behaviour.“ Personality and Social Psychology Review 8: 220-247.

SunsteIn, CASS R. (1995). „Incompletely Theorized Agreements.“ Harvard Law Review 108: 1733-1772.

Tetlock, PhiliP E. (1985). „Accountability. The Neglected Social Context of Judgement and Choice.“ Research in Organizational Behaviour 7: 297-332.

Tetlock, Philip E., Linda Skitka and Richard Boettger (1989). „Social and Cognitive Strategies for Coping with Accountability. Conformity, Complexity, and Bolstering." Journal of Personality and Social Psychology 57: 632-640.

Teubner, GunTHER (1989). Recht als autopoietisches System. Frankfurt, Suhrkamp. 
Wegner, Gerhard (1997). „Economic Policy from an Evolutionary Perspective. A New Approach.“ Journal of Institutional and Theoretical Economics 153: 485-509.

Weick, Karl E. (1995). Sensemaking in Organizations. Thousand Oaks, Sage Publications.

Wilson, Timothy D. and Jonathan W. Schooler (1991). „Thinking Too Much. Introspection can Reduce the Quality of Preferences and Decisions." Journal of Personality and Social Psychology 60: 181-192. 